\section{Resonancia magnética funcional en crisis parciales contínuas}

Sánchez-Marín C., León-Jiménez F.

Escuela de Medicina. Universidad Católica Santo Toribio de Mogrovejo. Chiclayo-Perú.

\section{Sr. Editor:}

Hemos leído con mucho interés el artículo publicado en el vol. 50, $\mathrm{N}^{\circ}$ 2, de I López et al, sobre el estatus parcial continuo, y el uso de la resonanciamagnética nuclear $(\mathrm{RMN})^{1}$. Ante todo quisiéramos felicitar a los autores por la calidad de reporte del caso clínico, de forma puntual y práctica acerca de todo lo descrito; además quisiéramos hacer hincapié en algunos detalles.

En la RMN se utiliza un fenómeno físico para absorber selectivamente energía electromagnética al colocarse bajo un campo magnético potente ${ }^{2}$. La resonancia magnética funcional (RMNf) mide ademas pequeños cambios metabólicos que ocurren en zonas activas del cerebro ${ }^{3}$.

En zonas donde hay una mayor actividad metabólica o neurológica, como por ejemplo, por algún foco epileptógeno, se generará una mayor captación de estas señales y por tanto, se evidenciará una hiperintensidad de la corteza afectada, sobre todo con señales en T2W-FLAIR (fluid-attenuaded inversión recovery) ${ }^{1}$.

En otros casos, como en las crisis parciales complejas asociadas a aneurismas, el mecanismo de la epileptogénesis es desconocido, pero la RMNf es igual de útil para evidenciar el foco epileptógeno ${ }^{2}$. Por ejemplo, en la imagen se visualiza áreas con edema cerebral en una paciente primigesta de 26 años con eclampsia y con TAC normal ${ }^{3}$.
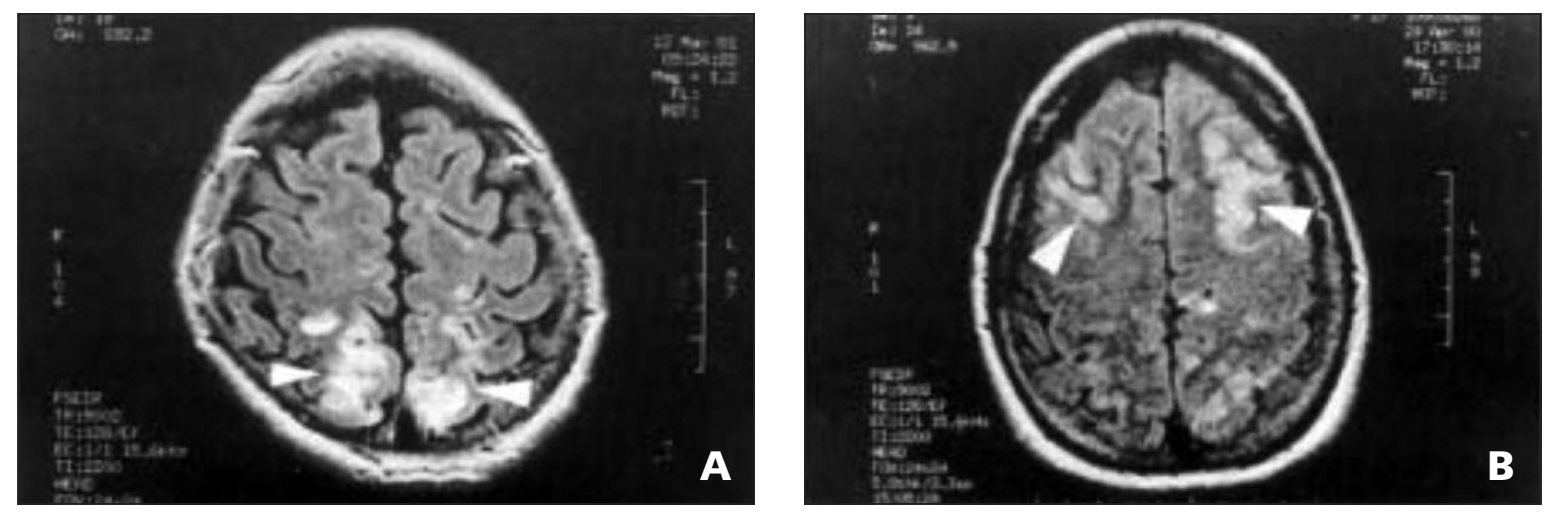

Resonancia nuclear magnética técnica FLAIR en planos axiales: A: imágenes bilaterales hiperintensas occipitales y, B: similares en regiones fronto-parietales compatibles con edema cerebral.

Por otra parte, en el último Curso Internacional de Neurociencia en la ciudad de Lima-Perú de este año, se hizo bastante énfasis en la utilidad e importancia de la RMNf en las lesiones focales de la corteza cerebral, sobre todo en las señales T2W-FLAIR, para buscar zonas de hiperintensidad que condicionarían un foco epileptogenico ya existentes en pacientes con epilepsia parciales y complejas 5 .

Para concluir, quisiéramos generar la inquietud de investigar, mediante el uso de RMNf, a las epilepsias generalizadas tipo ausencia, ya que se ha encon- trado hasta un 30\% de algún foco epileptógeno en el lóbulo temporal; estos condicionarían el desarrollo de la conocida epilepsia del lóbulo temporal del adulto $^{6}$; y si podría tener utilidad en el diagnóstico definitivo de otros tipos de epilepsias con o sin foco epileptógeno por imagenologia convencional.

\section{Referencias bibliográficas}

1. López I, González D, Quezada P, Cartier L. Estatus parcial continuo, causa de hiperintensidad de la 
corteza cerebral en la resonancia nuclear magnética. [Internet] Rev Chil Neuro-Psiquiat; Chile: 50 (2). p.112-116. 2012. [Acceso el 18 de octubre de 2012]. Disponible en: http://www.scielo.cl/scielo. php?pid=S0717-92272012000200005\&script $=$ sci_ arttext

2. Morales L, Álvarez A. Evaluación neurofuncional en pacientes con epilepsia del lóbulo temporal candidatos a cirugía. [Tesis en internet] Centro Internacional de Restauración Neurológica. 2004. [Acceso el 24 de octubre de 2012]. Disponible en: http://tesis.repo.sld.cu/439/1/tesis_doctoral_Lilia_Morales.pdf

3. Malvino E, Ríos J, Mc Loughlin D, Moreno A. Correlación clínica y neuro-radiologica en la eclampsia. [Artículo original] Medicina. Buenos
Aires 2004; 64 (6): 497-503.

4. Sandeep P, Cherian A, Iype T, Ayyappan K. A sac in a shaking uncus. [Internet] J Postgrad Med. India 2012; 58: 165-6. [Acceso el 24 de octubre de 2012]. Disponible en: http://www.jpgmonline. com/article.asp?issn=0022-3859; year $=2012$; volum $\mathrm{e}=58$; issue $=2$; page $=165$; epage $=166$; aulast $=$ Sande ep

5. XVIII Curso Internacional de Neurociencia. [Sede Web] Lima-Perú: 2012. [Acceso el 30 de octubre de 2012]. Disponible en: http://www.icn.minsa. gob.pe/index.php?option=com_content\&view= article\&id $=199$

6. Pérez P, Torrez E, Torrico G. Epilepsia. [Actualización] Rev Paceña Med Fam 2008; 5 (8): 92-101. [Acceso el 24 de octubre de 2012]. Disponible en: http://www.mflapaz.com/Revista\%208/Revista\%20 2\%20pdf/7\%20Epilepsia.pdf 